\title{
A review of nutritional and lifestyle interventions and guidelines for promoting maternal and child health in the interconception period
}

\author{
Daniella Watson ${ }^{1}$, Chandni Jacob ${ }^{1}$, Gareth Giles ${ }^{1}$, Fionnuala McAuliffe ${ }^{2}$, Keith Godfrey ${ }^{3}$, \\ and Mark Hanson ${ }^{1}$ \\ ${ }^{1}$ University of Southampton \\ ${ }^{2}$ UCD Perinatal Research Centre \\ ${ }^{3}$ Medical Research Council Environmental Epidemiology Unit, University of Southampton
}

December 22, 2021

\begin{abstract}
Background The interconception period is considered a time when parents are likely to engage with health messages and are in frequent contact with healthcare professionals. Objectives Through this literature review and policy analysis, we synthesised articles and guidelines on interconception care to provide recommendations to improve health outcomes for parents, infants and future generations. Search Strategy Four databases were searched systematically, using MeSH and free-text terms based on 'interconception' and 'postpartum'. Selection Criteria Selected articles included reviews, pilot studies and guidelines on interconception and postpartum interventions published in English by UK public health organisations and government agencies between 1st January 2010-12th January 2021. Data Collection and Analysis $30 \%$ of titles, abstracts and full-text papers were double-screened. The description table of identified guidelines were qualitatively analysed to generate categories, later developed into a framework of six domains. Findings are described using a narrative synthesis approach. Main Results We found 47 documents with guidelines, 29 reviews and six pilot studies on interconception and postpartum care. Interconception care opportunities include the postpartum period, family planning, routine practice, and risk assessments. Health and nonhealthcare professionals have a role to play in the interconception period including GPs, health visitors, dieticians, nutritionists, health psychologists, community groups, local authorities and charities such as Tommy's and First Step Nutrition. Conclusions The interconception and postpartum periods offer crucial opportunities to intervene to reduce possible long-term effects of suboptimal nutrition. Though the policy analysis for this review focused on the UK, the recommendations can have wider implications for other countries.
\end{abstract}

\section{Hosted file}

Interconception manuscript V7.docx available at https://authorea.com/users/452277/articles/ 550380-a-review-of-nutritional-and-lifestyle-interventions-and-guidelines-for-promotingmaternal-and-child-health-in-the-interconception-period

\section{Hosted file}

Figure 1 Interconception PRISMA.docx available at https://authorea.com/users/452277/articles/ 550380-a-review-of-nutritional-and-lifestyle-interventions-and-guidelines-for-promotingmaternal-and-child-health-in-the-interconception-period

\section{Hosted file}

Figure 2. Care opportunities for nutrition in the interconception period.pptx available at https://authorea.com/users/452277/articles/550380-a-review-of-nutritional-and- 
lifestyle-interventions-and-guidelines-for-promoting-maternal-and-child-health-in-theinterconception-period 